\title{
Syntheses of ${ }^{11} \mathrm{C}$ - and ${ }^{18} \mathrm{~F}$-labeled carboxylic esters within a hydrodynamically-driven micro-reactor
}

\author{
Shui-Yu Lua ${ }^{\mathrm{a}}$ Paul Watts ${ }^{\mathrm{b}}$, Frederick T. China ${ }^{\mathrm{a}}$, Jinsoo Hong ${ }^{\mathrm{a}}$, John L. Musachio ${ }^{\mathrm{a}}$, \\ Emmanuelle Briard $^{\mathrm{a}}$, and Victor W. Pike ${ }^{\mathrm{a}}$ \\ Shui-Yu Lu:Shuiyu.Lu@mail.nih.gov \\ aPET Radiopharmaceutical Sciences, Molecular Imaging Branch, National Institute of Mental \\ Health, National Institutes of Health, Room B3 C346, 10 Center Drive, Bethesda, MD \\ 20892-1003, USA

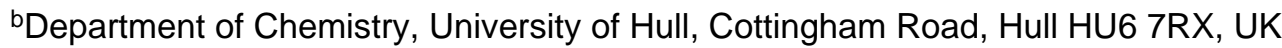

\section{Abstract}

Carboxylic esters were successfully labeled with one of two short-lived positron-emitters, carbon-11 or fluorine-18, within a hydrodynamically-driven micro-reactor. The non-radioactive methyl ester 4a was obtained at room temperature; its yield increased with higher substrate concentration and with reduced infusion rate. Radioactive methyl ester $\mathbf{4 b}$ was obtained from the reaction of $\mathbf{1}(10 \mathrm{mM})$ with $\mathbf{2 b}$ in $56 \%$ decay-corrected radiochemical yield (RCY) at an infusion rate of $10 \mu \mathrm{L} \mathrm{min}^{-1}$, and when the infusion rate was reduced to $1 \mu \mathrm{L} \mathrm{min}{ }^{-1}$, the RCY increased to $88 \%$. The synthesis of the non-radioactive fluoroethyl ester $\mathbf{5 a}$ from $\mathbf{1}$ and $\mathbf{3 a}$ required heating of the micro-reactor on a heating block at $80{ }^{\circ} \mathrm{C}(14-17 \% \mathrm{RCY})$, whilst the corresponding radioactive $\mathbf{5 b}$ from $\mathbf{1}$ and $\mathbf{3 b}$ was obtained in $10 \% \mathrm{RCY}$. The radioactive 'peripheral' benzodiazepine receptor ligand $\mathbf{7 b}$ was obtained from the reaction of acid $\mathbf{6}$ with labeling agent $\mathbf{2 b}$ in $45 \% \mathrm{RCY}$ at an infusion rate of $10 \mu \mathrm{L} \mathrm{min}{ }^{-1}$. When the infusion rate was reduced to $1 \mu \mathrm{L}$ $\mathrm{min}^{-1}$, the RCY increased to $65 \%$. The results exemplify a new methodology for producing radiotracers for imaging with positron emission tomography that has many potential advantages, including a requirement for small quantities of substrates, enhanced reaction, rapid reaction optimisation and easy product purification.

\section{Introduction}

Positron-emission tomography (PET) is a radiotracer imaging modality that is used to provide quantitative information on physiological and biochemical phenomena in animals and human subjects in vivo. ${ }^{1-3}$ Hence, this technique is valuable for clinical research ${ }^{4}$ and also for drug development. ${ }^{5-7}$ The biochemical scope and specificity of PET is determined by the available array of positron-emitting radiotracers, which are generally labeled with either carbon-11 $\left(t_{1 / 2}=20.4 \mathrm{~min}\right)$ or fluorine-18 $\left(t_{1 / 2}=109.7 \mathrm{~min}\right)$ at high (no-carrier-added; NCA) specific radioactivity. ${ }^{\dagger}$ These radiotracers, because of their short half-lives, must be

(C) The Royal Society of Chemistry 2004

Correspondence to: Shui-Yu Lu, Shuiyu. Lu@mail.nih.gov. 
produced as needed from cyclotron sources of carbon-11 and fluorine-18, which are usually $\left[{ }^{11} \mathrm{C}\right]$ carbon dioxide and $\left[{ }^{18} \mathrm{~F}\right]$ fluoride, respectively. The reliable and regular production of PET radiotracers is a major challenge to chemists. ${ }^{6}$ Such production must be performed in a lead-shielded hot-cell with remotely controlled and preferably automated equipment ${ }^{8-12}$ that is capable of (i) synthesis of the radiotracer from high initial levels of radioactivity (up to 5 $\mathrm{Ci} ; 1 \mathrm{Ci}=37 \mathrm{GBq}$ ), (ii) purification of the radiotracer and (iii) formulation of the radiotracer for intravenous injection, all within only two to three half-lives of the radioisotope.

Primary cyclotron irradiation products, such as $\left[{ }^{11} \mathrm{C}\right]$ carbon dioxide $\left(\left[{ }^{11} \mathrm{C}\right] \mathrm{CO}_{2}\right)$ and $\left[{ }^{18} \mathrm{~F}\right]$ fluoride $\left(\left[{ }^{18} \mathrm{~F}\right] \mathrm{F}^{-}\right)$, may be converted rapidly into alkylating agents such as $\left[{ }^{11} \mathrm{C}\right]$ iodomethane ${ }^{13-15}$ and $\left[{ }^{18} \mathrm{~F}\right] 2$-fluoroethyl tosylate. ${ }^{16,17}$ These are versatile labeling agents for introducing the radio-isotope into target radiotracers. ${ }^{18}$ Typically, a very large $\left(10^{2}-10^{4}\right.$-fold) excess of the non-radioactive reactant (precursor) is used in an alkylation reaction to promote rapid and efficient incorporation of the radioisotope into the target radiotracer. The reaction volume is typically 0.3 to $1.0 \mathrm{~mL}$ with the vessel sealed and heated. These conditions necessitate rapid separation of a low quantity of radioactive product (typically a few $\mu \mathrm{g}$ ) from a large excess of unreacted precursor (typically a few $\mathrm{mg}$ ); this represents a considerable challenge that is usually met with single pass HPLC on either a semi-preparative or full preparative column. Moreover, in practice, efficient transfers of radioactive product to HPLC are not always possible, since they may require intervening concentration of the reaction mixture by evaporation or the use of solid phase extraction.

Miniaturization of radiosyntheses with carbon-11 or fluorine-18 might lead to several benefits such as the use of less materials (especially precursor, which may be precious or difficult to obtain) and easier and faster purification with greater conservation of radioactive product and its specific radioactivity. Micro-reactor devices, ${ }^{19,20}$ consisting of a network of micron-sized channels (typical dimensions in the range 10-300 mm) etched into a solid substrate such as glass, are now emerging as an extremely useful technology for the intensification and miniaturization of chemical processes. The ability to manipulate reagent concentrations and reaction interfaces in both space and time within the channel network of a micro-reactor provides the fine level of reaction control that is desirable in PET radiochemistry practice. However, the application of micro-reactors in radiochemistry is so far very little explored, being limited to a single patent application. ${ }^{21}$

In this communication we report the use of a simple hydrodynamically-driven micro-reactor for radiosynthesis with carbon-11 and fluorine-18, exemplified by radiosyntheses of NCA ${ }^{11} \mathrm{C}$ - and ${ }^{18} \mathrm{~F}$-labeled esters (Scheme 1). Esters are commonly encountered functional groups in PET radiotracers, and they may be labeled by reactions of carboxylic acid salts with, for example, $\left[{ }^{11} \mathrm{C}\right]$ iodomethane $\left.(\mathbf{2 b})\right)^{22}$ or $\left[{ }^{18} \mathrm{~F}\right] 2$-fluoroethyl tosylate $(\mathbf{3 b}) .{ }^{23}$

\footnotetext{
${ }^{\dagger}$ Specific radioactivity is the ratio of the amount of radioactive compound $(\mathrm{Ci})$ to non-radioactive counterpart known as carrier (mol). The specific radioactivities of no-carrier-added ${ }^{11} \mathrm{C}$ - or ${ }^{18} \mathrm{~F}$-labeled compounds typically far exceed $1 \mathrm{Ci}_{\mu \mathrm{mol}}{ }^{-1}$ at the end of synthesis. The specific radioactivity is a time-variable parameter which decreases with radioactive decay.
} 


\section{Experimental}

All chemicals were used as received from commercial sources except where stated otherwise. Compound 6 was synthesized according to a published method. ${ }^{24}$

The micro-reactor is a T-shaped channel [220 $\mathrm{mm}(\mathrm{W}) \times 60 \mu \mathrm{m}(\mathrm{D}) \times 14 \mathrm{~mm}(\mathrm{~L})$; total volume $\sim 0.2 \mu \mathrm{L}]$ located at the interface of two bonded borosilicate glass layers. It has two entry ports (A and B), each connected to a gas-tight micro-syringe (Hamilton) powered by a precision syringe pump (Harvard), and one exit port (C) leading to a collection reservoir (Scheme 2).

Reactions in the micro-reactor were first investigated with non-radioactive reagents. In a typical experiment, syringe A was loaded with a solution of $\mathbf{1}$ (concentration set in the range 2-10 mM) plus tetra- $n$-butylammonium hydroxide of equal concentration in DMF (200 $\mu \mathrm{L})$ and syringe B was loaded with a solution of the alkylating agent (2a or 3a) of the same concentration in DMF $(200 \mu \mathrm{L})$. A portion of the solution $(10 \mu \mathrm{L})$ in each syringe was then infused simultaneously and at an equal set rate (in the range 0.5 to $10 \mu \mathrm{L} \mathrm{min}^{-1}$ ) through the micro-reactor. The reaction mixture output at port $\mathrm{C}$ was quenched continuously by dilution in acetonitrile $(0.5 \mathrm{~mL}) \ddagger$ A portion $(25 \mu \mathrm{L})$ of the quenched reaction mixture was injected onto a HPLC column (C 18; Luna; $10 \mu \mathrm{m} ; 4.6 \times 250 \mathrm{~mm}$; Phenomenex) eluted with acetonitrile (B) $-0.01 \mathrm{M}$ aqueous ammonium formate (A) with a gradient of $30 \% \mathrm{~B}$ to $80 \% \mathrm{~B}$ over $10 \mathrm{~min}$ at $1 \mathrm{~mL} \mathrm{~min}{ }^{-1}$. Conversions of acid into ester were estimated from the UV absorbance areas in the chromatogram (Beckman Gold). Decay-corrected radiochemical yields (RCYs) were calculated from the peak areas of the product and unreacted starting material (Bioscan). The products were identified by both co-elution of reference product and LC-MS analysis of the selected fraction.

\section{Results and discussion}

We selected reactions of 3-(3-pyridinyl)propionic acid (1) with $\mathbf{2} \mathbf{b}$ or $\mathbf{3 b}$ to test the feasibility of radiosyntheses with short-lived radioisotopes within a simple micro-reactor. Reactions were also run similarly with the precursor acid $\mathbf{6}$ to produce the peripheral benzodiazepine receptor (PBR) ligand, $7 \mathbf{a}$ (Scheme 3). ${ }^{24,25}$

Radiosyntheses with 1 were conducted similarly, except that syringe B was loaded with a solution of $\mathbf{2 b}$ in DMF or $\mathbf{3 b}$ in DMF ( $1 \mathrm{mCi} ; \sim 375$ or $\sim 200 \mathrm{mCi} \mu \mathrm{mol}^{-1}$, corresponding to $0.03 \mathrm{mM}$ or $0.05 \mathrm{mM}$, respectively; $100 \mu \mathrm{L}$ ) and the volume in syringe A was similarly reduced to $100 \mu \mathrm{L}$.

For the non-radioactive reactions of $\mathbf{1}$ with $\mathbf{2 a}$, the methyl ester $\mathbf{4 a}$ was obtained at room temperature, and its yield increased with higher reagent concentration and with reduced infusion rate (Fig. 1). The same trend is also observed in reactions with radioactive

\footnotetext{
\#Dilution in acetonitrile was shown to be a convenient and simple means for quenching the progress of the alkylation reactions. For example, a reaction of $\mathbf{1}$ with 2a giving a yield of $38 \%$, progressed by only a further $3 \%$ over 70 min after quenching by dilution in acetonitrile. The effect of acetonitrile addition on the reaction of $\mathbf{1}$ with $\mathbf{3 a}$ was similar.

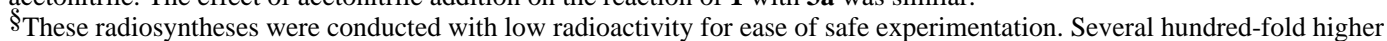
radioactivity concentration would be feasible, the upper limit only being determined by the technique of producing the labeling agent.
} 
materials. For example, as illustrated in Fig. 1, at an infusion rate of $10 \mu \mathrm{L} \mathrm{min}^{-1}$ the radioactive methyl ester $\mathbf{4 b}$ was obtained from the reaction of $\mathbf{1}(10 \mathrm{mM})$ with $\mathbf{2 b}$ in $56 \%$ $\mathrm{RCY}(n=2)$, and when the infusion rate was reduced to $1 \mu \mathrm{L} \mathrm{min}{ }^{-1}$, the RCY increased to $88 \%(n=2)$. The lower infusion rate allows more time in the micro-reactor (residence time) for reactant mixing by diffusion, and for reaction. At $1 \mu \mathrm{L} \mathrm{min}{ }^{-1}$ the residence time is about $12 \mathrm{~s}$ and total processing time $10 \mathrm{~min}$, the latter is comparable to reaction times currently used in PET radiotracer synthesis. With new micro-reactor designs ${ }^{26}$ it should be possible to achieve thorough mixing of reagents at higher infusion rates, so further accelerating the process.

The synthesis of the fluoroethyl ester 5a from $\mathbf{1}$ and 3a did not proceed at room temperature and required heating of the micro-reactor on a heating block at $80{ }^{\circ} \mathrm{C}$ to achieve moderate yields (14-17\%). The reaction can be performed with as low as $0.75 \mu \mathrm{g}(5 \mathrm{nmol})$ of 1 in 10 $\mu \mathrm{L}$ of solution (Fig. 2). At an infusion rate of $1 \mu \mathrm{L} \mathrm{min}-1$, reactions of 1 with the labeling agent $\mathbf{3 b}$ at $80{ }^{\circ} \mathrm{C}$ gave the ${ }^{18} \mathrm{~F}$-labeled ester $\mathbf{5 b}$ in $10 \% \mathrm{RCY}$.

This approach was further exemplified by the synthesis of a ligand 7a and its labeling with carbon-11 as a prospective radioligand $\mathbf{7 b}$ for PET imaging of brain 'peripheral' benzodiazepine receptors. At an infusion rate of $10 \mu \mathrm{L} \mathrm{min}-1,7 \mathbf{b}$ was obtained from the reaction of acid $\mathbf{6}$ with labeling agent $\mathbf{2 b}$ in $45 \% \mathrm{RCY}$, and when the infusion rate was reduced to $1 \mu \mathrm{L} \mathrm{min}-1$, the RCY increased to $65 \%$ (Fig. 3).

It should be noted that the radioactive reaction mixtures obtained from the micro-reactor are easily and rapidly separable on an analytical HPLC column, because only low amounts of material are present in a low volume. The radiotracer may be obtained from the HPLC in a smaller volume which in turn facilitates its easier formulation for safe intravenous administration.

\section{Conclusions}

We have demonstrated, as proof of principle, that the synthesis of $\mathrm{NCA}^{11} \mathrm{C}$ and ${ }^{18} \mathrm{~F}$-labeled carboxylic esters is rapid and efficient in a simple hydrodynamically-driven glass microreactor. These results exemplify some of the potential advantages of this methodology for radiotracer synthesis, which should be amenable to greater sophistication to encompass entire radiosyntheses in a versatile high throughput manner.

\section{References}

1. Phelps ME, Mazziotta JC. Science. 1985; 228:799. [PubMed: 2860723]

2. Phelps ME. Neurochem. Res. 1991; 16:929. [PubMed: 1784338]

3. Phelps ME. Proc. Natl. Acad. Sci. USA. 2000; 97:9226. [PubMed: 10922074]

4. Wagner HN. J. Nucl. Med. 1991; 32:561. [PubMed: 1849557]

5. Comar, D., editor. Dev. Nucl. Med. No 26. Dordrecht: Kluwer; 1995. PET for Drug Development and Evaluation.

6. Pike VW. Drug Information J. 1997; 31:997.

7. Burns HD, Hamill TH, Eng W-S, Francis B, Fioranti C, Gibson RE. Curr. Opin. Chem. Biol. 1999; 2:388. [PubMed: 10419855] 
8. Fowler, JS.; Wolf, AP. The Synthesis of Carbon-11, Fluorine-18 and Nitrogen-13 Labeled Radiotracers for Biomedical Applications. Technical Information Center, US Department of Energy; 1982.

9. Stöcklin, G.; Pike, VW. Radiopharmaceuticals for Positron Emission Tomography: Methodological Aspects. Dordrecht: Kluwer Academic Publishers; 1993.

10. Fowler JS, Wolf AP. Acc. Chem. Res. 1997; 30:181.

11. Elsinga PH. Methods. 2002; 27:208. [PubMed: 12183108]

12. Welch, MJ.; Redvanly, CS. Handbook of Radiopharmaceuticals, Radiochemistry and Applications. Chichester: John Wiley \& Son Ltd.; 2003.

13. Crouzel C, Langström B, Pike VW, Coenen HH. Appl. Radiat. Isot. Intl. J. Appl. Instrument. Part A. 1987; 38:601.

14. Larsen P, Ulin J, Dahlstroem K, Jensen M. Appl. Radiat. Isot. 1997; 48:153.

15. Link JM, Krohn KA, Clark JC. Nucl. Med. Biol. 1997; 24:93. [PubMed: 9080480]

16. Block D, Coenen HH, Stöcklin G. J. Labelled Compd. Radiopharm. 1987; 24:1029.

17. Studenov AR, Berridge MS. Nucl. Med. Biol. 2001; 28:683. [PubMed: 11518650]

18. Iwata R. Reference Book for PET Radiopharmaceuticals. 2002TohokuCYRICAvailable at: http:// kakuyaku.cyric.tohoku.ac.jp/public/Reference_Book_2002.pdf. Comprehensive list of PET radiopharmaceutials and useful secondary labeling agents and intermediates.

19. Fletcher PD, Haswell SJ, Pombo-Villar E, Warrington BH, Watts P, Wong SYF, Zhang X. Tetrahedron. 2002; 58:4735. This is a comprehensive review of the fabrication and application of micro reactors in organic synthesis up to 2002.

20. Ehrfeld, W.; Hessel, V.; Löwe, H. Microreactors-New Technology for Modern Chemistry. Weinheim: Wiley-VCH; 2000.

21. Brady F, Luthra SK, Gillies JM, Geffery NT. PCT, WO 03/078358 A2. 2003 This is the first patent literature to disclose the application of micro reactors to the synthesis of radiolabelled compound, specific examples include the synthesis of 2 - $\left[{ }^{18} \mathrm{~F}\right]$ fluorodeoxyglucose $(\mathrm{FDG})$ and $\left[{ }^{11} \mathrm{C}\right] \mathrm{N}-$ methylations.

22. Bolton R. J. Labelled Compd. Radiopharm. 2001; 44701 and references therein.

23. Lu SY, Chin FT, McCarron JA, Pike VW. J. Labelled Compd. Radiopharm. 2004; 47:289.

24. Okubo T, Yoshikawa R, Chaki S, Okuyama S, Nakazato A. Bioorg. Med. Chem. 2004; 12:423. [PubMed: 14723961]

25. Nakazato, A.; Okubo, T.; Nakamura, T.; Chaki, S.; Tomisawa, K.; Nagamine, M.; Yamamoto, K.; Harada, K.; Yoshida, M. US Patent. 6,476,056B2. 2002.

26. Johnson TJ, Ross D, Locascio LE. Anal. Chem. 2002; 74:45. [PubMed: 11795815] The autors reported a simple yet effective method to a create slanted well along the T-micro channel imprinted on polymeric substrate. Polymers, such as polypropyrene, are widely used in instruments for PET synthesis. 


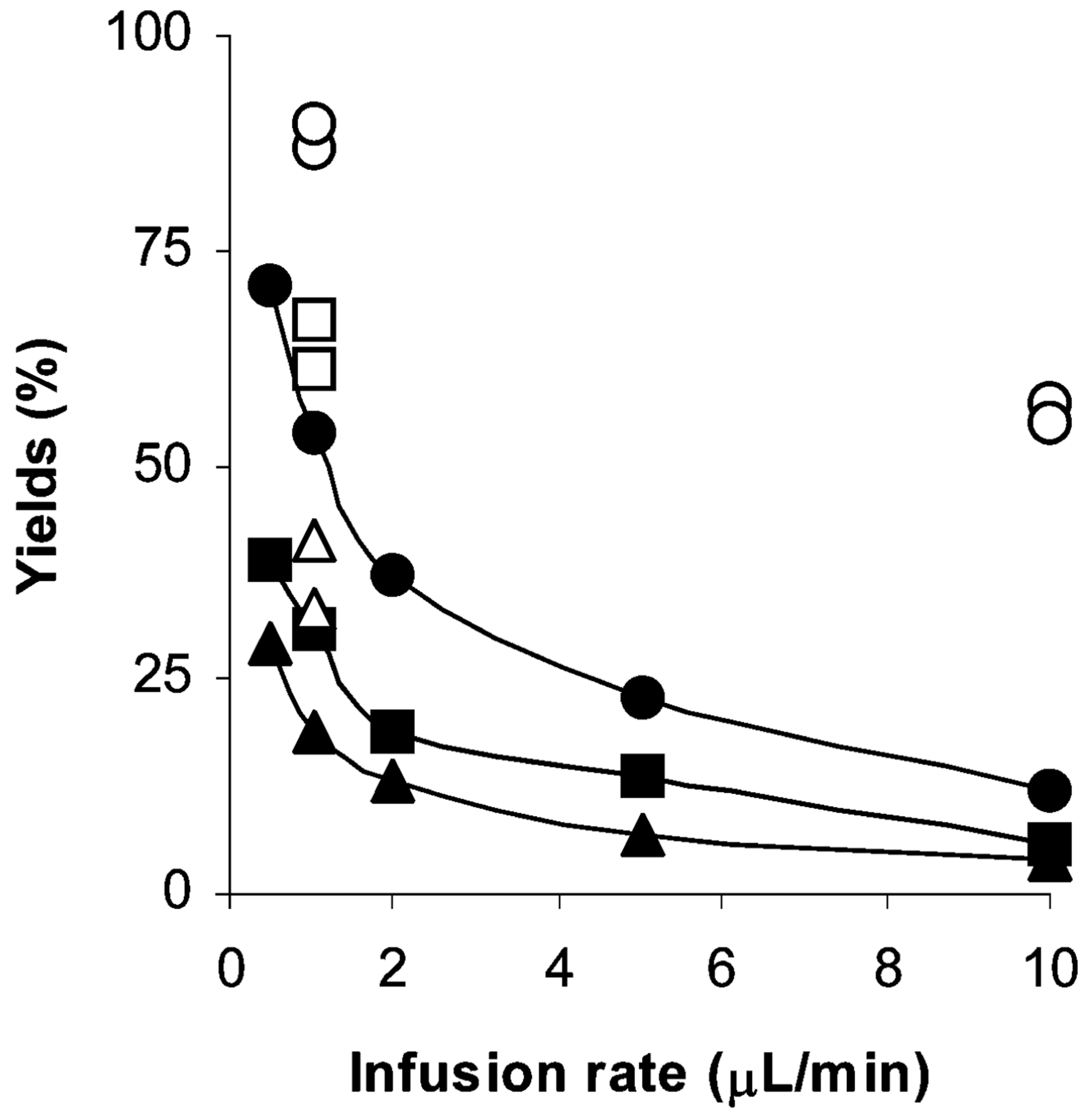

Fig. 1.

Effect of infusion rate and reagent concentration on the yield of ester $4 \mathbf{a}$ from the reactions of acid $\mathbf{1}(10 \mathrm{mM})$ with $\mathbf{2 a}(10 \mathrm{mM})(\mathbf{O}) ; \mathbf{1}(5 \mathrm{mM})$ with $\mathbf{2 a}(5 \mathrm{mM})(\mathbf{\square}) ; \mathbf{1}(2 \mathrm{mM})$ with $\mathbf{2 a}$ $(2 \mathrm{mM})(\mathbf{\Delta})$ and RCYs of ${ }^{11} \mathrm{C}$-labeled ester $\mathbf{4 b}$ from the reaction of acid $\mathbf{1}(10 \mathrm{mM})$ with $\mathbf{2 b}$ $(\bigcirc), \mathbf{1}(5 \mathrm{mM})$ with $\mathbf{2 b}(\square)$ and $\mathbf{1}(2 \mathrm{mM})$ with $\mathbf{2 b}(\triangle)$. All reactions were performed at room temperature. 


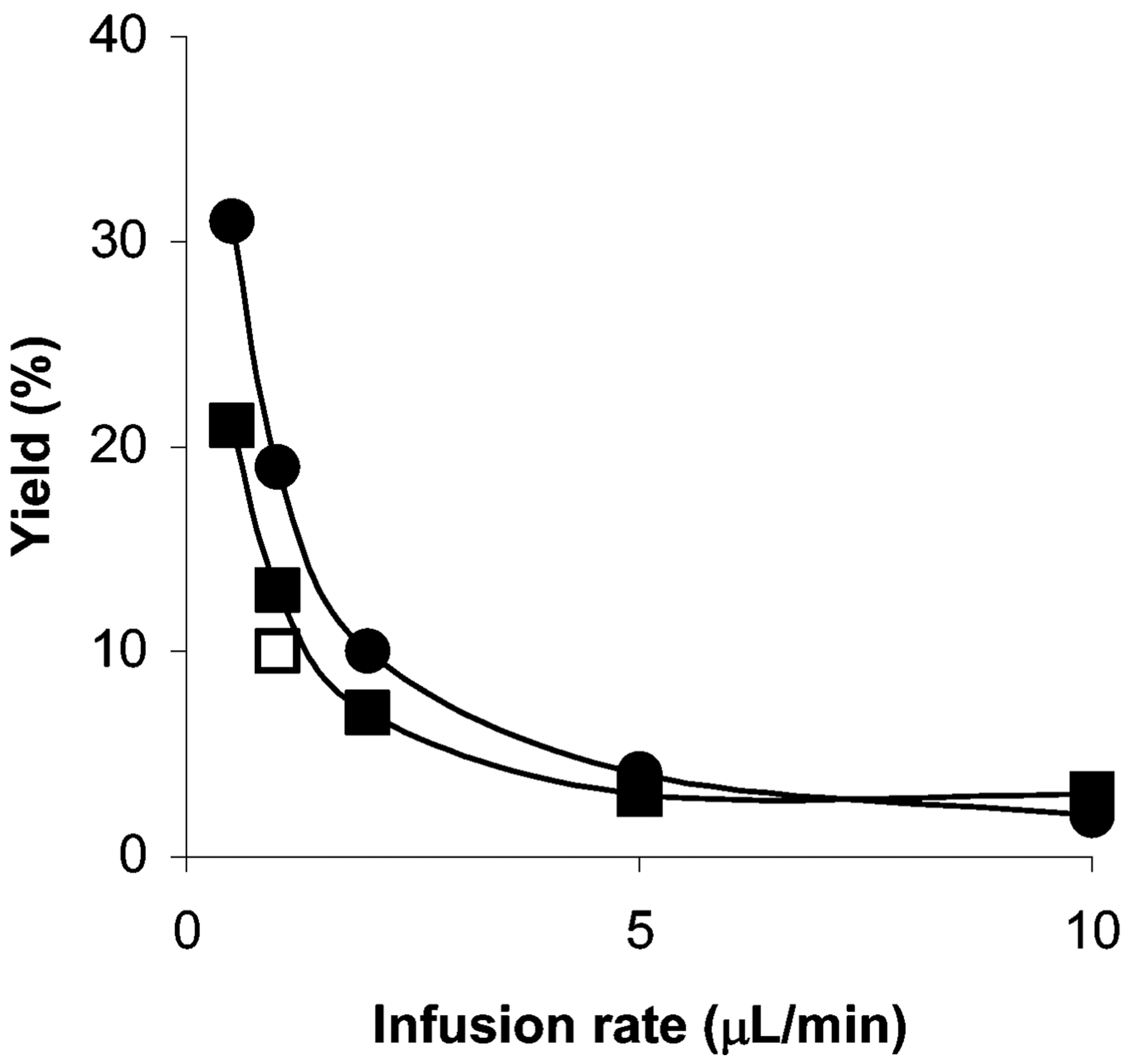

Fig. 2.

Effect of infusion rate and reagent concentration on the yield of ester $\mathbf{5 a}$ from the reaction of acid $\mathbf{1}(10 \mathrm{mM})$ with $\mathbf{3 a}(10 \mathrm{mM})(\mathbf{0})$ and $\mathbf{1}(5 \mathrm{mM})$ with $\mathbf{3 a}(5 \mathrm{mM})(\mathbf{\square})$ at $80^{\circ} \mathrm{C}$ in DMF, and the RCY of ester $\mathbf{5 b}$ from the reaction of acid $\mathbf{1}(5 \mathrm{mM})$ with $\mathbf{3 b}$ at $80{ }^{\circ} \mathrm{C}(\square)$. 


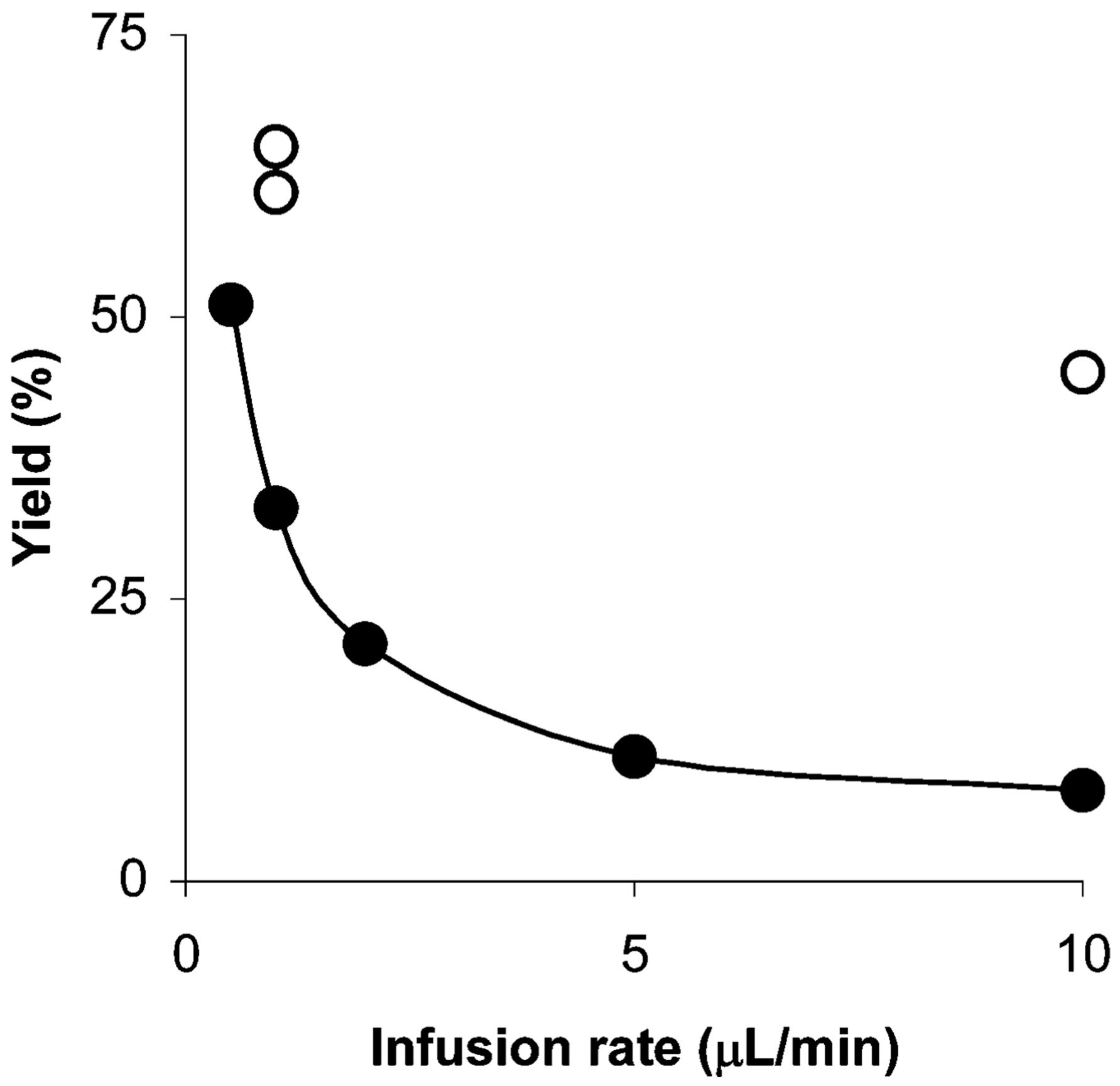

Fig. 3.

The effect of infusion rate on the yield of ester 7a from the reaction of acid $6(5 \mathrm{mM})$ with $\mathbf{2 a}(5 \mathrm{mM})(\mathbf{O})$ and the RCYs of ester $7 \mathbf{b}$ from the reaction of acid $\mathbf{6}(5 \mathrm{mM})$ with $\mathbf{2 b}(\bigcirc)$. All reactions were performed at room temperature. 
<smiles>[R]OC(=O)CCc1cccnc1</smiles>

1

2a $\mathrm{CH}_{3} \mathrm{I}$

2b ${ }^{11} \mathrm{CH}_{3} \mathrm{l}$

3a $\mathrm{FCH}_{2} \mathrm{CH}_{2} \mathrm{OTs}$

3b ${ }^{18} \mathrm{FCH}_{2} \mathrm{CH}_{2} \mathrm{OTs}$ 4a $\mathrm{R}^{\prime}=\mathrm{CH}_{3}$

4b $\mathrm{R}^{\prime}={ }^{11} \mathrm{CH}_{3}$

5a $\mathrm{R}^{\prime}=\mathrm{FCH}_{2} \mathrm{CH}_{2}$

5b $\mathrm{R}^{\prime}={ }^{18} \mathrm{FCH}_{2} \mathrm{CH}_{2}$

Scheme 1.

Labeling of carboxylic esters with ${ }^{11} \mathrm{C}$ or ${ }^{18} \mathrm{~F}$. 


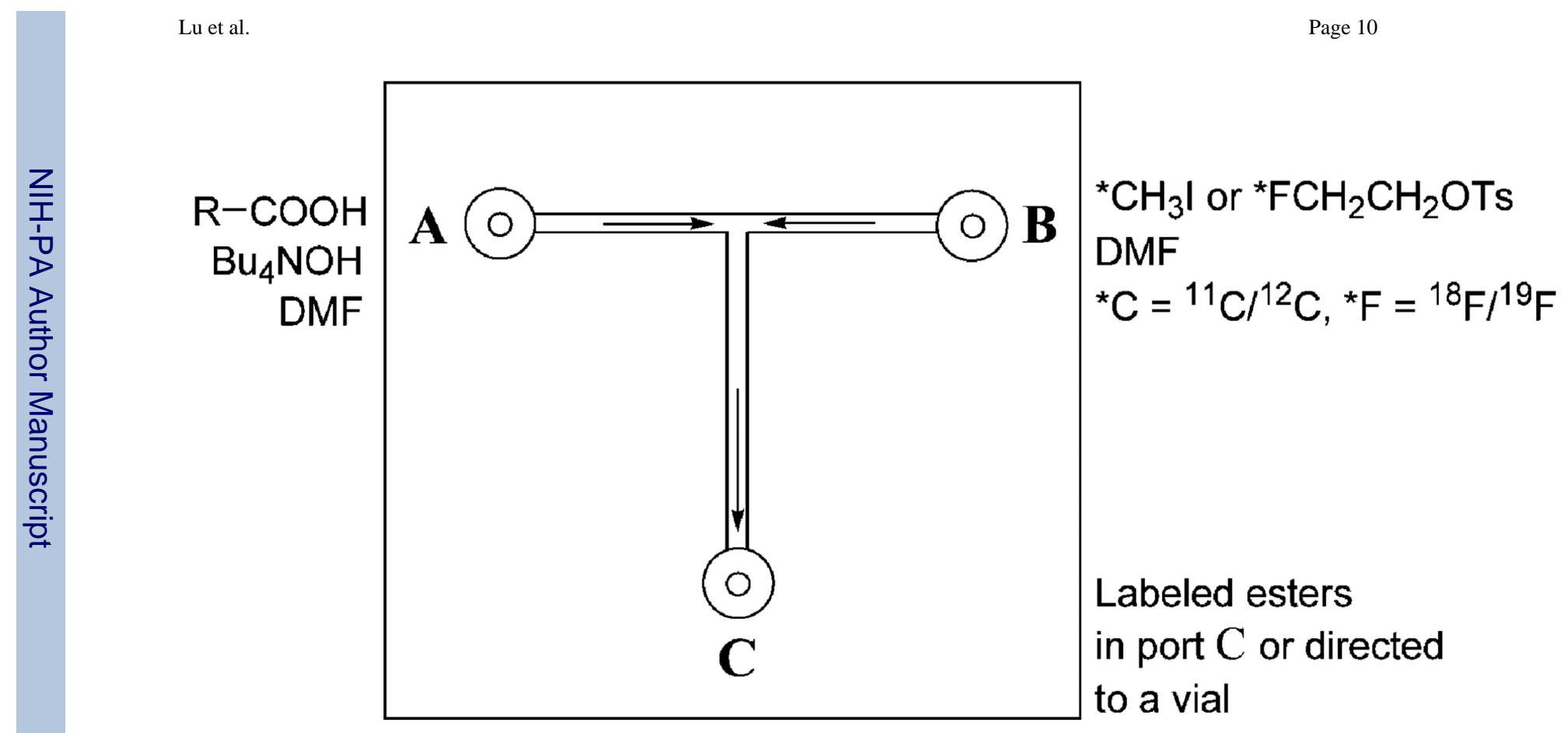

Scheme 2.

Schematic representation of the reagent placement and flow direction within the micro reactor. 


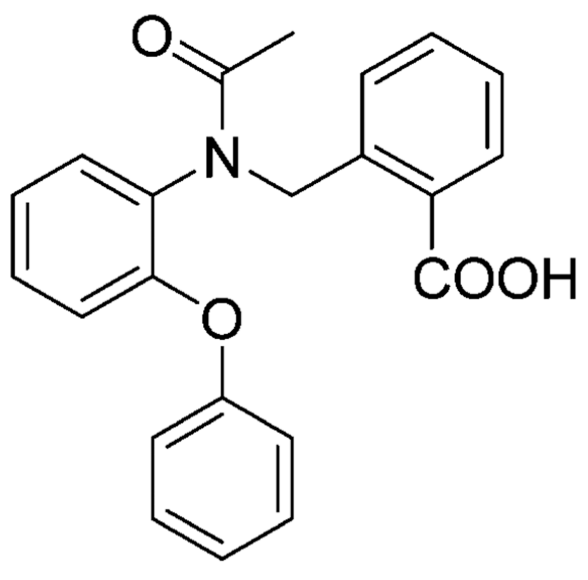

6

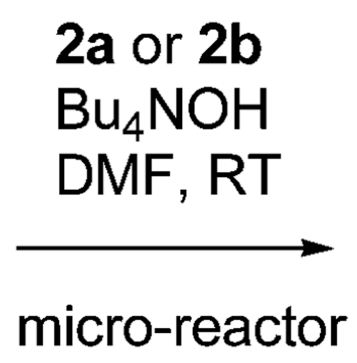

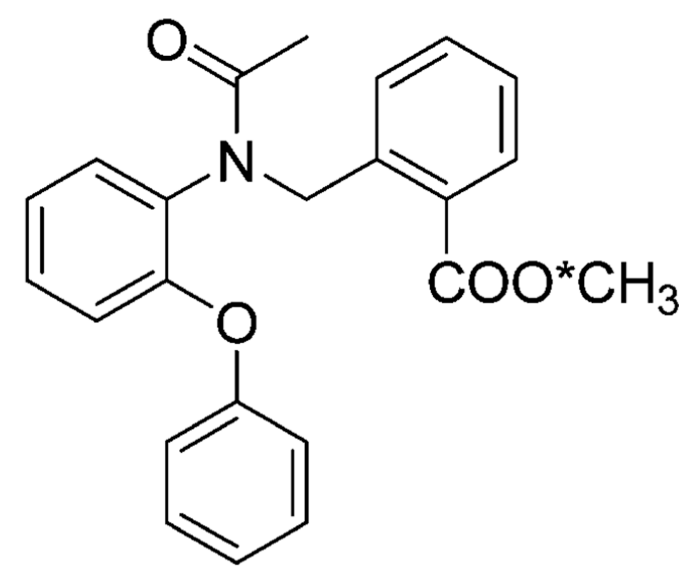

$7 \mathrm{a}{ }^{*} \mathrm{C}={ }^{12} \mathrm{C}$ $7 b{ }^{*} \mathrm{C}={ }^{11} \mathrm{C}$

Scheme 3.

Synthesis of non-radioactive or ${ }^{11} \mathrm{C}$-labeled peripheral benzodiazepine receptor ligand. 